\title{
Canopy Light Interception of a Conventional and an Erect Leafed Sorghum
}

\author{
Dennis C. Gitz III*, Zhanguo Xin, Jeffrey T. Baker, Robert J. Lascano, John J. Burke \\ Cropping Systems Research Laboratory, USDA-ARS\#, Lubbock, TX, USA \\ Email: "dennis.gitz@ars.usda.gov
}

Received 16 September 2015; accepted 18 October 2015; published 21 October 2015

Copyright (C) 2015 by authors and Scientific Research Publishing Inc.

This work is licensed under the Creative Commons Attribution International License (CC BY).

http://creativecommons.org/licenses/by/4.0/

c) (i) Open Access

\begin{abstract}
Two sorghum lines, an erect leafed mutant sorghum and the wild type from which the mutant was generated, were field grown in rectilinear arrays at low (10 plants $\left.\mathrm{m}^{-2}\right)$ and high (23 plants $\left.\mathrm{m}^{-2}\right)$ population densities. Canopy light interception, biomass accretion and yield were measured. Photosynthetically active radiation under the canopy at ground level and midway through the canopy were higher in the erect leafed line, as compared to the normal leafed line. Planting density had less effect on mean grain yield and biomass in the erect leaf line than in the wild type. Though not conclusive, when taken together, the results suggested that optimal planting densities are higher for the erect leaf line and that the erect leaf trait could be useful for incorporation into breeding programs.
\end{abstract}

\section{Keywords}

Sorghum, Erectophile, Mutant, Erect Leaf

\section{Introduction}

The eu-sorghums (Sorghum bicolor L.) were domesticated between 2000-5000 years ago. While there is some evidence that sorghum could have existed in neolithic China [1], it is now generally accepted that the plant's

\footnotetext{
*Corresponding author.

\#The US Department of Agriculture (USDA) prohibits discrimination in all its programs and activities on the basis of race, color, national origin, age disability, and where applicable, sex, marital status, familial status, parental status, religion, sexual orientation, genetic information, political beliefs, reprisal, or because all or part of an individual's income is derived from any public assistance program. (Not all prohibited bases apply to all programs.) Persons with disabilities who required alternative means for communication of program information (Braille, large print, audiotape, etc.) should contact USDA's TARGET Center at (202) 720-2600 (voice and TDD). To file a complaint of discrimination, write to USDA, Office of Civil Rights, 1400 Independence Avenue, S.W., Washington, D.C. 20250-9410, or call (800) 795-3272 (voice) or (202) 720-6382 (TDD). USDA is an equal opportunity provider and employer.
}

How to cite this paper: Gitz III, D.C., Xin, Z., Baker, J.T., Lascano, R.J. and Burke, J.J. (2015) Canopy Light Interception of a Conventional and an Erect Leafed Sorghum. American Journal of Plant Sciences, 6, 2576-2584.

http://dx.doi.org/10.4236/ajps.2015.616260 
origin is Africa where the wild representatives are exclusively found. There is no discrete center of sorghum distribution; rather, landraces are found across the African continent [2]. Extant sorghum races can freely interbreed and are found in semi-arid to wet and from tropical to temperate climes. The lack of a center of domestication, the expansive spatial and climatic ranges, and the ability to freely interbreed between both cultivars and landraces have all contributed to the considerable genetic diversity of this plant. There are tens of thousands of sorghum landraces, mutant genotypes, classical cultivars, and modern commercial hybrids; and this does not consider the closely related species that could be exploited for inclusion in classical breeding or in germplasm maintenance operations. The United States sorghum germplasm collection alone has more than 40,000 entries, and many other collections exist [3].

Sorghum has been used as a stress tolerant crop plant since being brought to the new world [4]. Landraces from hot dry regions of Africa were brought to the Americas during the mid 1800's where the resiliency of the crop was exploited. Because of sorghum's stress tolerance, including drought stress tolerance, North American bankers would require that sorghum be planted alongside higher value but drought sensitive grain crops such as corn (Zea mays L.) to minimize credit default risk in the early 1900's. Attempts to further enhance drought tolerance by exploiting sorghum's diversity in selective breeding programs were proposed at the turn of the last century [5] [6]. However, interest in such programs waned when internal combustion engine powered irrigation insured reduced variability in production of corn, and of other more marketable and hence valuable crops [7]. Continually increasing demand for such crops has resulted in expansion of irrigated crop production systems. As a result demand for finite irrigation water continues to increase. Because of increased demand and because irrigation water is a finite resource, irrigation water availability is becoming increasingly limited worldwide. Irrigation water limitation has led to renewed interest in selection of drought tolerant, or more water use efficient sorghum (e.g., [8]-[11]).

Despite the diversity in sorghum germplasm, breeding programs have met with limited success exploiting existing traits for enhanced crop water use efficiency and drought tolerance. For such reasons, mutant libraries have been created to compliment the considerable diversity of landraces and cultivars in modern germplasm collections. These mutant libraries (putatively) offer an array of mendelian heritable traits that could be exploited in breeding programs attempting to exploit characteristics conferring increased productivity or at least maintaining agricultural productivity in the face of decreasing supplies of water suitable for crop irrigation.

Earlier, a mutant sorghum population was created and described which displayed several traits that could prove useful for incorporation into grain, forage, and biomass production systems [12]. Among the traits expressed in this population were brown midrib, multiple tillers, late flowering, increased and reduced epicuticular wax production, and erect leafed sorghum plants. Erect leafed sorghum is especially attractive since exposing both leaf surfaces to sunlight leads to more efficient radiation use and the smaller footprint allows for higher population densities, both of which could result in higher yields on a land area basis and increased crop water use efficiencies. Herein, we report the effect of stand density upon biomass accretion, yield, and light interception of a recently described erect leafed mutant sorghum as compared to the wild type from which it was derived [13].

\section{Materials and Methods}

\subsection{Overview}

Two sorghum lines from the USDA sorghum mutant library [13] were planted and allowed to develop. Light within the canopies was quantified diurnally. A preliminary experiment was done in a controlled environment polyhouse to determine the upper planting density to use in subsequent field work in which yield parameters were additionally quantified.

\subsection{Plant Material and Culture}

Sorghum (Sorghum bicolor L.) seeds were planted in a climate controlled polyhouse or in the field at the USDA nursery in Lubbock, TX $\left(33^{\circ} 35^{\prime} 38.00^{\prime \prime} \mathrm{N}, 101^{\circ} 54^{\prime} 10.50 " \mathrm{~W}\right)$. Two sorghum lines were used in the experiments, BTx623 [14] and an erect leafed mutant derived and isolated from the BTx623 parent line, ERL-1a [13].

In the polyhouse $\left(30^{\circ} / 18^{\circ}\right.$, Day/Night; uncontrolled humidity; no supplemental lighting), black polyethylene containers ( $20 \mathrm{~cm}$ diameter, $4 \mathrm{~L}$ capacity) were filled with a soil-less peat based commercial horticultural potting 
mix (Sunshine Traditional Loose Fill mix; Sungro Horticultural Products ${ }^{1}$, Bellvue, WA; www.sungro.com), the rooting medium was saturated to field capacity by irrigating to runoff several times over about an hour, and several [3]-[5] sorghum seeds were then pushed about $2.5 \mathrm{~cm}$ into the growth medium into the center of each container. After about seven days the first true leaf was clearly visible and the group of plants was thinned to a single individual. The plants were fertigated daily with an automated horticultural drip delivery system to well past the drip point with a complete nutrient solution. The nutrient solution consisted of $11 \mathrm{~kg}$ of Peter's ExCel Multipurpose fertilizer (Scotts Company LLC, Marysville OH) brought to 189 liters and subsequently injected into the irrigation water at a ratio of 1:150 (v:v, fertilizer solution:municipal water). The plants were allowed to develop until they were between the milk and soft dough developmental stages [15] when light interception was characterized.

In the field, seeds were planted into $5 \times 10$ m plots with a garden planter (Model 1001-B, Earthway ${ }^{\circledR}$, Bristol IN) using a radish seed plate (Pt. No. 1002-5) that had been modified to accept sorghum seeds by carefully enlarging the with a small spherical high speed rotary file. Seeds were planted on DOY 166 in the 2011 growing season in $19 \mathrm{~cm}$ (High Density) or $38 \mathrm{~cm}$ (Low Density) east-west rows. In an attempt to insure even emergence and minimize developmental variation along and across treatments, the plots were irrigated through subsurface drip irrigation (SDI) lines running north-south, perpendicular to the planting rows, spaced at $1 \mathrm{~m}$ and $20-25 \mathrm{~cm}$ below the soil surface. Immediately after planting $2.5 \mathrm{~cm}$ of water was applied to the field through SDI was used to "wet up" the soil. After emergence the stands were thinned so remaining plants were equidistantly spaced in either a $34 \mathrm{~cm} \times 34 \mathrm{~cm}$ or $17 \times 17 \mathrm{~cm}$ rectilinear arrays. There were sixteen plots with four plots per genotype $\times$ treatment $(\mathrm{n}=4)$. Actual measured populations after thinning operations and establishment were determined at harvest to be $10.0 \pm 0.4$ plants $\mathrm{m}^{-2}$ and $22.9 \pm 1.7$ plants $\mathrm{m}^{-2}$ (mean \pm S.E.) A small stand of sweet corn at the far end of the field planted over the same SDI drip tubing running under the sorghum plots. Because the sorghum and corn plots were simultaneously irrigated and because corn is considerably more responsive to drought stress, corn was used as bio-indicator of soil moisture through the season. Irrigations were applied to prevent the corn from exhibiting symptoms of water stress such as erect rolled leaves and a lighter green color. The sorghum exhibited no obvious symptoms of drought stress during the growing season. The soil at the Lubbock USDA location is an Amarillo fine sandy loam (fine-loamy, mixed, superactive, thermic Aridic Paleustalfs).

\subsection{Radiation Measurement}

In the polyhouse photosynthetically active radiation (PAR) was quantified within canopies simulated by arranging container grown plants along a bench. This was done to estimate how population density might affect light within the canopy micro-environment in field grown plants, and to help select population densities for field experimentation. The container grown conventional or erect leafed mutant sorghum lines were arranged along two benches centered within and along the north-south axis of the polyhouse. Forty eight plant containers were arranged in a $6 \times 8$ rectangular array with the long axis of the array oriented north-south. The benches were placed along the center-line of the polyhouse one to the north of the other with a four meter space between the two canopies to minimze shading. Linear quantum sensors were horizontally and equidistantly suspended from a structural central beam within each canopy at 30,60,90, and $120 \mathrm{~cm}$ above the surface of the rooting medium to quantify PAR. A separate linear PAR sensor was mounted above the canopy on the horizontal lower chord of the polyhouse roof truss. The ambient light sensor was oriented, east-west, perpendicular to the canopy PAR sensors.

In the field, PAR within the canopy was measured at ground level, and midway up the canopy at the onset of boot on a clear day, DOY 221, with a device assembled in the lab (Figure 1). The device used two 1m linear PAR sensors (Model LI-191 Line Quantum Sensor, LiCor ${ }^{\circledR}$ Environmental Inc., Lincoln NE) held perpendicular to a $2 \mathrm{~m}$ extruded aluminum staff. One of the linear sensors was mounted permanently at ground level and the support for the other sensor's height above the ground was adjustable. The height of the second linear PAR sensor was adjustable and was set so that the sensor height was at about half the canopy height. One point PAR sensor (LiCor ${ }^{\circledR}$ Model LI-190 Quantum Sensor) above the canopy to measure radiation above the canopy. Data were recorded using a datalogger (LI-1400 Data Logger). The PAR readings were taken along the north side of where the instrument was inserted into the canopy towards the south. After inserting the probes into the canopy,

${ }^{1}$ Mention of trade names or commercial products in this publication is solely for the purpose of providing specific information and does not imply recommendation or endorsement by the US Department of Agriculture. 


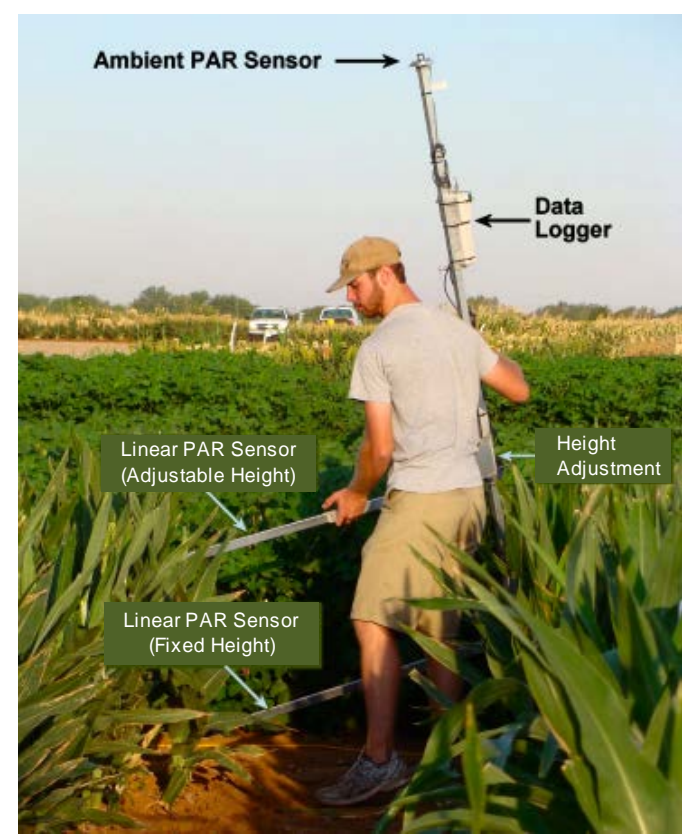

Figure 1. Apparatus for measurement of light within field grown sorghum canopies.

the staff was held vertical as indicated by spirit levels mounted on the sides of the staff and the outputs from all three PAR sensors simultaneously recorded as $\mu \mathrm{mol} \cdot \mathrm{m}^{-2} \cdot \mathrm{s}^{-1}$ of PAR, along with the time of the measurements. Care was taken to avoid inserting the probes directly along the solar azimuth to avoid shading of the ground level sensor by the mid-canopy sensor, especially around solar noon. This was accomplished by offsetting the probe away from the solar azimuth by about $15^{\circ}$; inserting the probe towards the SSW or SSE just before or after solar noon, respectively. Averages from three locations in each plot were taken. Measurements were started each hour from sunrise to sunset. Each pass through the field was completed in one half hour; about 30 minutes. For presentation, the \% transmitted radiation that is, the percentage of ambient radiation incident upon the linear PAR sensors plus or minus standard deviation about the mean was calculated and plotted as a function of the time of day; where the time of day was defined as the average of individual sampling times. Transmitted radiation was plotted for presentation rather than intercepted radiation because interpretation of the data was found to be more intuitive.

\subsection{Canopy Development and Yield}

The Leaf Area Index (LAI) of the plants, the area of the leaves within the crop canopy above the soil surface area (leaf area/soil surface area), was measured in situ with a fisheye lens canopy analyzer (LAI-2200, LiCor ${ }^{\circledR}$ Inc.) shortly after dawn on DOY 222. For each plot, the average of four measurements was calculated and recorded. Leaf area of five individual plants within each plot was measured with a LI-3100 benchtop leaf area meter. Above ground plant biomass was determined by drying plants at $60^{\circ} \mathrm{C}$ for several days and noting the mass.

\section{Results}

The PAR within the synthetic canopy, constructed by arranging container grown sorghum plants in a $20 \mathrm{~cm} \times 20$ $\mathrm{cm}$ array in the polyhouse on a clear day, is shown in Figure 2. Note that relative transmittance (\%) of ambient light and absolute light levels $\left(\mu \mathrm{mol} \cdot \mathrm{m}^{-2} \cdot \mathrm{s}^{-1}\right)$ within the greenhouse were plotted in the figure(s) rather than intercepted radiation. Consequentially, the uppermost curves resulted from the uppermost linear PAR sensors. At times, the calculated transmittance of the uppermost line sensors within the canopies was higher, up to 105\%, that of the line sensor used for ambient values. This resulted from occasional shading of the ambient PAR sensor by the polyhouse architecture. Rather than assume $100 \%$ transmittance, these data were deleted from the presentation. A mid-day decrease in measured radiation within the canopy was observed. This radiation decrease 


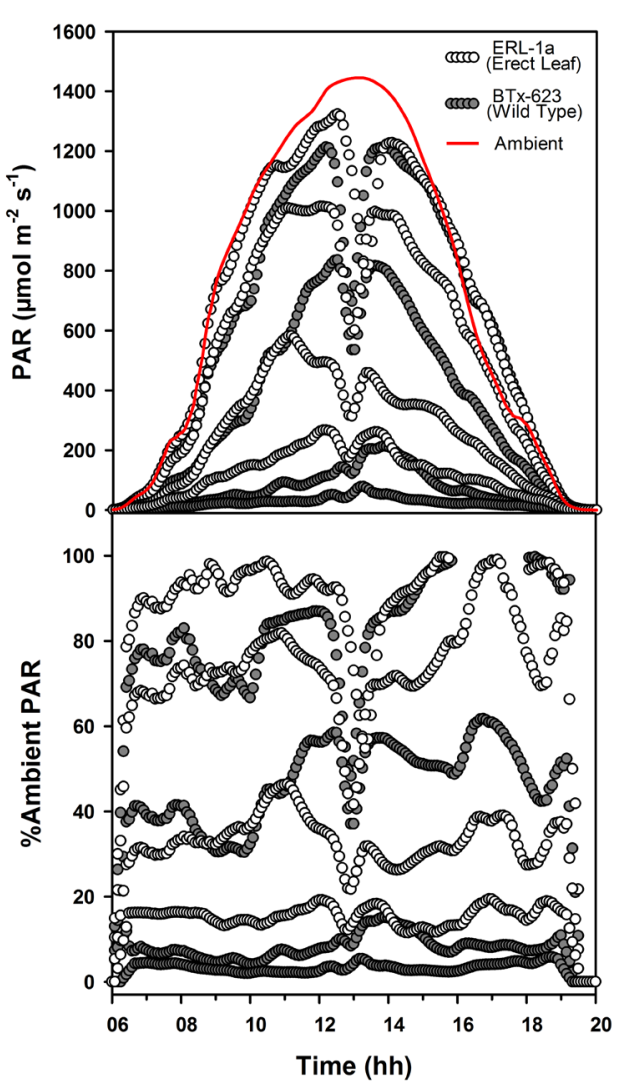

Figure 2. Photosynthetically active radiation (Upper Pane) and calculated Transmittance (Lower Pane) of light within an artificially constructed sorghum canopy in a greenhouse. Open symbols are measurements from within erect leaved sorghum. Closed symbols are from within conventional sorghum. Upper curves are from higher in canopy and lower curves are from deeper within the canopy. Red line is PAR above canopies.

occurred at solar noon and was observed in all sensors in both canopies and resulted from the direct component of solar radiation being occluded by a central North-South roof support beam from which the linear PAR sensors were suspended. Because the ambient line sensor was mounted elsewhere and above beams that could cast such shadows, the calculated transmission at solar noon is a measure of the indirect component of radiation moving through the canopy. While the translucent polyethylene roof of the polyhouse seemed to diffuse radiation similar to a high clouds in a field setting, it is unknown how the angular distribution of PAR within the polyhouse compares to such conditions. Angular distribution of PAR was not quantified in the field or in the polyhouse. Even so, PAR clearly decreased as one moved deeper into both the wild type and erect leafed canopies throughout the day and measured PAR was consistently greater within the erect leafed ERL-1a sorghum canopy as compared to that within the Btx-623 canopy.

A view of the field grown wild type (Btx-623) and mutant (ERL-1a) sorghum lines is shown in Figure 3. Visual inspection reveals a considerably more open canopy in the erect leafed line as compared to the conventional sorghum. The leaves appeared to adopt an erect orientation as might be expected from corn leaves when rolling in response to water deficit. However, the leaves of the erect sorghum were not rolled but appeared corrugated.

Measurements of ambient radiation and of light within field plots are shown in Figure 4. The sky was clear throughout the day on which the measurements were made. Ambient PAR exhibited the classical sinusoidal temporal distribution centered about solar noon expected from whole sky solar radiation with minimal indirect component (Figure 4(A)). As expected, PAR within densely planted sorghum (High Density) canopies was less 

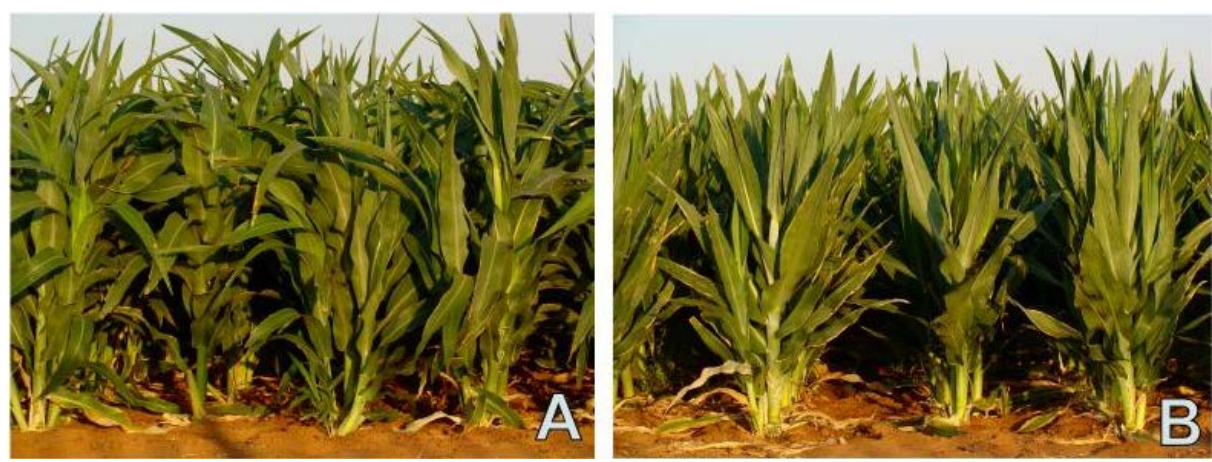

Figure 3. (A) conventional and (B) erect leafed sorghum in field.

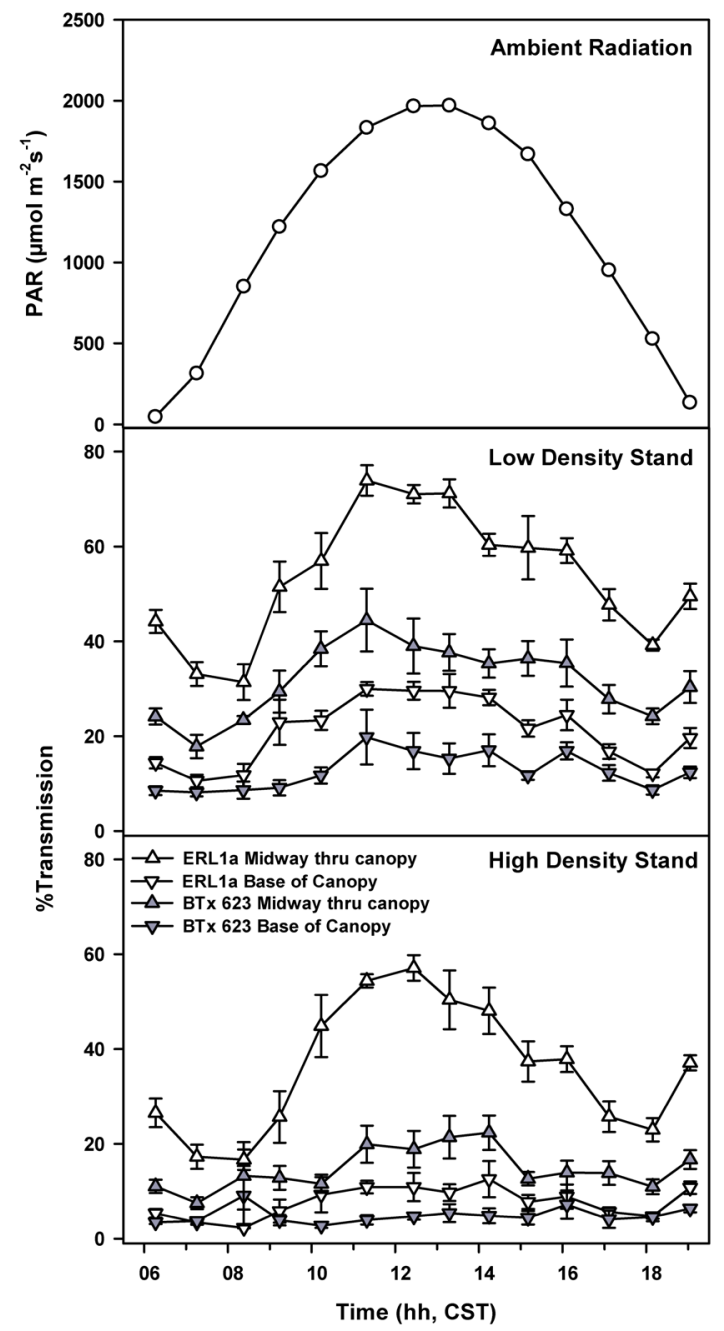

Figure 4. Ambient radiation (top pane) and percentage of ambient radiation with canopies of erect leafed and conventional sorghum planted at "Low Density" (10 plants $\mathrm{m}^{-2}$, middle pane) and "High Density" (23 plants $\mathrm{m}^{-2}$, bottom pane).

than that of less densely planted (Low Density) canopies and decreased as one moved deeper within the canopy (Figure 4(B) \& Figure 4(C)). Erect leaved sorghum allowed a greater amount of PAR to pass through the canopy at each planting density and at each level within the canopy especially near solar noon when the solar angle was not as oblique and canopy transmission was less affected by plant to plant shading. 
In general, every measured yield parameter measured was lower as compared to the conventional sorghum, except for seed size which was nearly identical between lines (not shown). Yield differences observed resulted from differences in the numbers of seeds rather than individual seed size. The leaf area of individual plants measured by detaching leaves and individually feed them through a leaf area meter decreased by about $50 \%$ with a doubling of plant population density (Figure 5(A)). Biomass (Figure 5(C)) and yield (Figure 5(D)) exhibited similar responses to density. However, the partitioning of accreted dry matter towards grain production was enhanced at the higher planting densities. That is, grain yield decreased less than yield. Yield decreases resulted from a decrease in seed numbers and not from a decrease in seed size (not shown). Leaf area index measured by optical methods was indistinguishable within planting density treatments, but exhibited higher variation with the erect leaf variety. This was attributed to the "clumpy" nature of the ERL-1a canopy.

\section{Discussion}

The idea of a high yielding wheat ideotype having several morphological characteristics including erect leaves was discussed about a half century ago [16]. Since then, results from work comparing erect leaf phenotypes to more horizontal leaf orientations have yielded mixed results. Studies with barley [17] provided no clear evidence that erect leaf angle enhanced grain yield while others reported yield increases of $25 \%$ in rice [18] and a $40 \%$ increase has been reported for corn [19]. Indirect solar radiation is the component of whole sky radiation that erect leaves are thought to best take advantage. Differences in the proportion of direct to indirect radiation might explain the differences in results between researchers attempting to evaluate the effect of the erect leaf phenotype on crop yield. The present work was conducted in a semi-arid region with a large number of very clear days with no perceptible haze. The contribution of direct radiation to whole sky solar irradiance is much
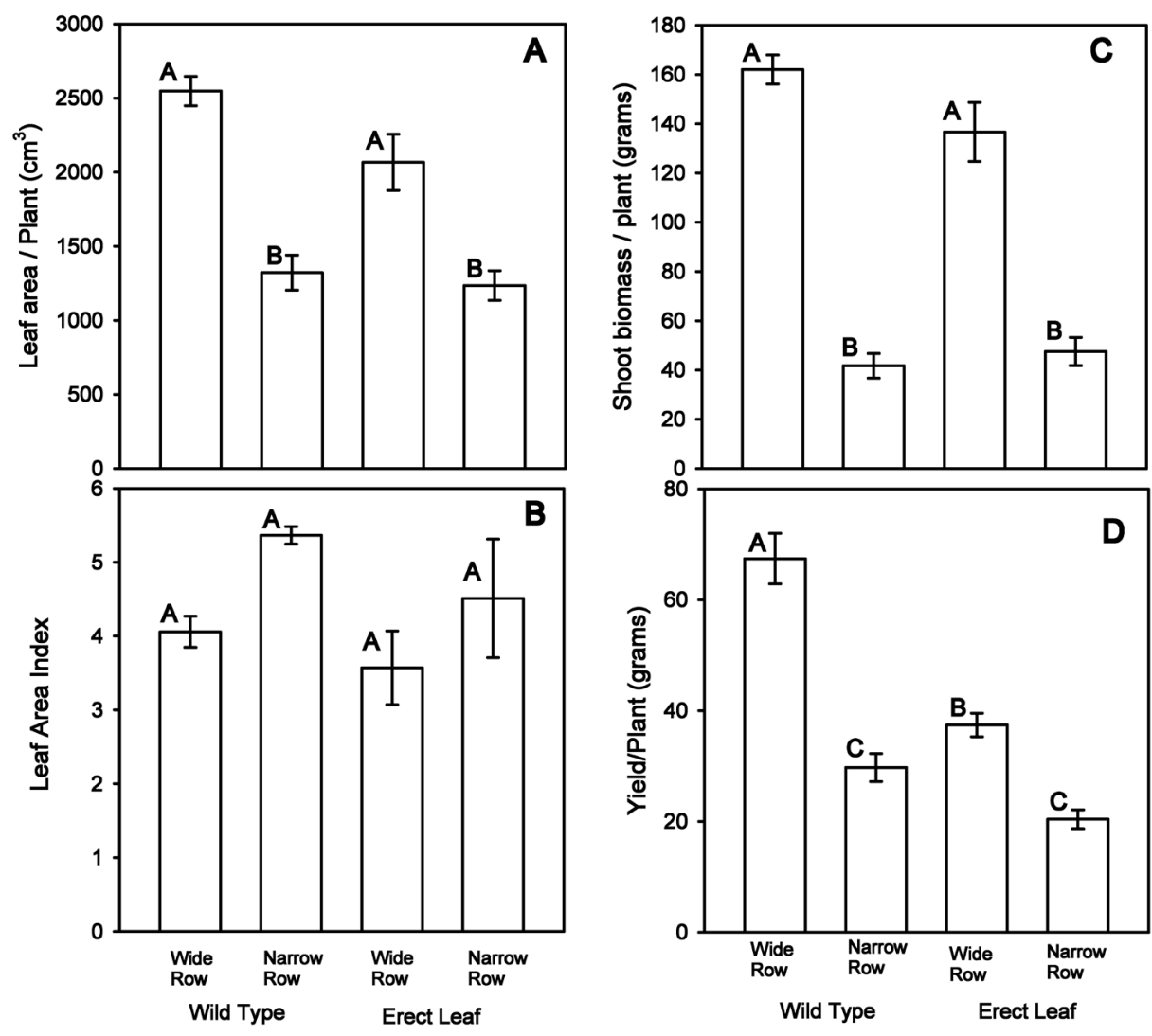

Figure 5. Canopy leaf area indices (left) and yield response (right) of erect leafed and conventional sorghums. (A) Leaf area of individual plants; (B) leaf area indices of canopies measured by optical methods; (C) whole above ground plant biomass; (D) seed yield of individual plants. Bars are standard error about the mean. Results of means separation by ANOVA at 0.95\% error with Bonferroni correction are shown to left of bars. 
greater than in other regions. Even though direct experimental comparisons between erectophiles and more conventional or "lax leaved" crops have yielded mixed results, many modern crop cultivars have erect leaves. The mechanistic underpinnings for potential yield increases in erectophiles remain an active research topic. It is unknown whether reported yield increases, or the relative insensitivity of yield to crop density, have resulted from more complete interception of radiation [20], altered distribution of radiation within the canopy leading to altered distribution of photosynthesis within the canopy [21], or reduction in leaf sensecence from increased light penetration. Moreover it may not be as simple as selecting for erect leaves throughout the canopy. Selecting for erect upper leaves and more prostrate interior leaves has been attempted in maize breeding programs [22]. Nevertheless, it is generally accepted that increasing leaf angle from horizontal to verticle results in higher canopy photosynthesis. It has been estimated that increasing leaf angle from $30^{\circ}$ to $60^{\circ}$ can result in canopy photosynthesis increase of up to $15 \%$ in corn [23].

In the present study it is difficult to draw inferences with regard to the effect of the erect leaf trait on optimal planting density since the trait is associated with a reduction seed yield even at lower population densities. Based on seed yield data alone it would appear that the trait is not useful for incorporation into breeding programs. However, while seed yield of the erect leaf mutant was intrinsically less than that of the conventional line, erect leaf seed yield was also less responsive to population density. That is, seed yield decreased less with the erect leafed sorghum as compared to the conventional leafed sorghum. This suggests that the optimal plant population density of the erect leafed plant is higher than that of the conventional line. While this makes sense from a simple radiation interception perspective, another result of this was that carbon partitioning as grain/shoot biomass approached nearly 50\% with the erect leafed sorghum at higher planting densities (Figure 5(C) \& Figure 5(D)). It is generally accepted that source-sink relationships are involved with the biochemical regulation of photosynthesis. For such reasons increased sink size might also be associated with enhanced water use efficiencies at higher population densities.

\section{Acknowledgements}

We thank Dr. Lan Liu-Gitz for helpful discussions and suggestions through the course of this work and also Messrs. Cody Byars and Peyton Schuman for their technical assistance during the experimental phase of the work. This project was funded in part by the USDA-ARS Ogallala Aquifer Program.

\section{References}

[1] De Candolle, A. (1886) Plants Cultivated for Their Seeds. In: Origin of Cultivated Plants, 2nd Edition, International Scientific Series Vol. XLIX, Kegan Paul Trench \& Co., London, 376-384. https://archive.org/download/originofcultivat00cand/originofcultivat00cand.pdf

[2] Harlan, J.R. (1971) Agricultural Origins: Centers and Non-Centers. Science, 174, 468-474. http://dx.doi.org/10.1126/science.174.4008.468

[3] Dahlberg, J., Berenji, J., Sikora, V. and Latkovic, V. (2011) Assessing Sorghum [Sorghum bicolor (L.) Moench] Germplasm for New Traits: Food, Fuels \& Unique Uses. Maydica, 56, 85-92. http://www.maydica.org/articles/56 165.pdf Hu, T. and Desai, J.P. (2004) Soft-Tissue Material Properties under Large Deformation: Strain Rate Effect. Proceedings of the 26th Annual International Conference of the IEEE EMBS, San Francisco, 1-5 September 2004, 2758-2761.

[4] Borman, T.A. (1914) Sorghums: Sure Money Crops. The Kansas Farmer Company, Topeka. http://dx.doi.org/10.5962/bhl.title.43352

[5] Ball, C.R. (1913) The Grain Sorghums: Immigrant Crops That Have Made Good. In: Yearbook of Agriculture, US Department of Agriculture, 221-238. http://naldc.nal.usda.gov/naldc/download.xhtml?id=IND43747834\&content=PDF

[6] Martin, J.H. (1936) Sorghum Improvement. In: Yearbook of Agriculture, US Department of Agriculture, 523-560.

[7] Musick, J.T., Pringle, F.B., Harman, W.L. and Stewart, B.A. (1990) Long-Term Irrigation Trends-Texas High Plains. Applied Engineering in Agriculture, 6, 717-724. http://dx.doi.org/10.13031/2013.26454

[8] Rosenow, D.T., Quisenberry, J.E., Wendt, C.W. and Clark, L.E. (1983) Drought Tolerant Sorghum and Cotton Germplasm. Agricultural Water Management, 7, 207-222. http://dx.doi.org/10.1016/0378-3774(83)90084-7.

[9] Blum, A., Mayer, J. and Golan, G. (1989) Agronomic and Physiological Assessments of Genotypic Variation for Drought Resistance in Sorghum. Australian Journal of Agricultural Research, 40, 49-61. http://dx.doi.org/10.1071/ar9890049 
[10] Fussell, L.K., Bidinger, F.R. and Bieler, P. (1991) Crop Physiology and Breeding for Drought Tolerance: Research and Development. Field Crops Research, 27, 183-199. http://dx.doi.org/10.1016/0378-4290(91)90061-y

[11] Mutava, R.N., Prasad, P.V.V., Tuinstra, M.R., Kofoid, K.D. and Yua, J. (2011) Characterization of Sorghum Genotypes for Traits Related to Drought Tolerance. Field Crops Research, 123, 10-18. http://dx.doi.org/10.1016/j.fcr.2011.04.006

[12] Xin, Z., Wang, M.L., Burow, G. and Burke, J.J. (2009) An Induced Sorghum Mutant Population Suitable for Bioenergy Research. BioEnergy Research, 2, 10-16. http://dx.doi.org/10.1007/s12155-008-9029-3

[13] Xin, Z., Gitz, D.C., Chen, J., Burow, G.B., Hayes, C. and Burke, J.J. (2015) Registration of Two Allelic Erect Leaf Mutants of Sorghum. Journal of Plant Registrations, 9, 254-257. http://dx.doi.org/10.3198/jpr2014.09.0060crgs

[14] Frederiksen, R.A. and Miller, F. (1972) Proposal for Release and Increase ATx622, BTx622, ATx623, BTx623, ATx624, BTx624. TAES Form 96-72: Seed Release Committee of the Texas Agricultural Experiment Station College Station.

[15] Vanderlip, R.L. and Reeves, H.E. (1972) Growth Stages of Sorghum [Sorghum bicolor, (L.) Moench.]. Agronomy Journal, 64, 13-16. http://dx.doi.org/10.2134/agronj1972.00021962006400010005x

[16] Donald, C.M.T. (1968) The Breeding of Crop Ideotypes. Euphytica, 17, 385-403. http://dx.doi.org/10.1007/bf00056241

[17] Tungland, L., Chapko, L.B., Wiersma, J.V. and Rasmusson, D.C. (1987) Effect of Erect Leaf Angle on Grain Yield in Barley. Crop Science, 27, 37-40. http://dx.doi.org/10.2135/cropsci1987.0011183X002700010009x

[18] Khush, G.S. (1995) Breaking the Yield Frontier of Rice. GeoJournal, 35, 329-332. http://dx.doi.org/10.1007/BF00989140

[19] Pendleton, J.W., Smith, G.E., Winter, S.R. and Johnston, T.J. (1968) Field Investigations of the Relationships of Leaf Angle in Corn (Zea mays L.) to Grain Yield and Apparent Photosynthesis. Agronomy Journal, 60, 422-424. http://dx.doi.org/10.2134/agronj1968.00021962006000040027x

[20] Feil, B. (1992) Breeding Progress in Small Grain Cereals-A Comparison of Old and Modern Cultivars. Plant Breeding, 108, 1-11. http://dx.doi.org/10.1111/j.1439-0523.1992.tb00093.x

[21] Angus, J.F., Jones, R. and Wilson, J.H. (1972) A Comparison of Barley Cultivars with Different Leaf Inclinations. Crop and Pasture Science, 23, 945-957. http://dx.doi.org/10.1071/ar9720945

[22] Ghannoum, O. (2013) Potential Contribution of Increased Photosynthetic Efficiency to Increased Yield Potential of Maize. Applying Photosynthesis Research to Improvement of Food Crops, ACIAR Proceedings \#140, Proceedings of a Workshop Held at the Australian National University, Canberra, Australian Capital Territory, Australia, 2-4 September 2009, 70-76. http://aciar.gov.au/files/pr140_web.pdf

[23] Tollenaar, M. and Dwyer, L.M. (1999) Physiology of Maize. In: Smith, D.L. and Hamel, C., Eds., Crop Yield, Physiology and Processes, Springer Verlag, Berlin, 169-204. http://dx.doi.org/10.1007/978-3-642-58554-8_5 